\title{
Pesquisa e Metodologia em Michel Foucault
}

\author{
João Leite Ferreira Neto ${ }^{1}$ \\ Pontifícia Universidade Católica de Minas
}

\begin{abstract}
RESUMO - Estuda-se contribuições teórico-metodológicas de Foucault, realçando seu uso de elementos metodológicos clássicos. O artigo se organiza em três eixos analíticos: o exame de fragmentos da obra desse autor, especialmente de seus Cursos; aproximações de sua perspectiva com a literatura contemporânea sobre pesquisa qualitativa; e a análise de textos nos quais ele explicita suas escolhas metodológicas. Acentua-se sua opção de estudar problemas a partir de "suas formas mais singulares e concretas". Explora-se o delineamento, concomitantemente clássico e inovador, de sua pesquisa derradeira da genealogia do sujeito moderno analisando as razões de suas escolhas metodológicas. Considera-se que a construção de problemas de pesquisa relevantes, associada ao trabalho detalhado e preciso, contribuiu para o impacto incisivo de sua obra.
\end{abstract}

Palavras-chave: Foucault, metodologia, pesquisa qualitativa

\section{Research and Methodology of Michel Foucault}

\begin{abstract}
This is a study about Foucault's theoretical and methodological contributions, highlighting the use of classical methodological elements. The paper is organized in three analytical axes: the examination of fragments of Foucault's works; associations between his perspectives and the contemporary literature on qualitative research; and the analysis of texts in which his methodological choices are expressed. Foucault's option of studying problems from their "most singular and concrete forms" is pointed out. The design of his last project, which is simultaneously classic and innovative, is explored, with highlight to his detailed methodological choices. The construction of relevant research problems associated with his detailed and accurate way of working is considered to have contributed to the profound impact of his work.
\end{abstract}

Keywords: Foucault, methodology, qualitative research

Se quisermos colocar problemas de forma rigorosa, precisa e apta a levantar interrogações sérias, não é preciso ir procurá-las, justamente, em suas formas mais singulares e concretas? (Foucault, 1980/2010a, p.335).

Foucault tem se tornado uma referência destacada nas pesquisas em ciências humanas e sociais no Brasil e no exterior, notadamente nos países anglo-saxões. Utilizado em áreas como psicologia (na qual fez graduação), medicina, psiquiatria, direito, história, geografia, educação, sociologia, linguística (particularmente nos estudos em análise do discurso), antropologia e ciências políticas. Sua influência aumentou após sua morte em 1984, favorecida pela publicação póstuma de suas entrevistas e artigos, e de seus Cursos no Collège de France, tornando difícil um estudo exaustivo sobre a literatura secundária baseada em sua obra (Lemke, 2012).

Nas pesquisas em psicologia no Brasil a referência à Foucault é extensa e crescente. Foi realizado um levantamento em março de 2014 na base de dados Scielo através do descritor "Psicologia" combinado com o nome de variados filósofos. Foucault aparece em 89 entradas, seguido por Deleuze em 32 e por Adorno em 26. A análise de como esse uso é efetivado foge ao escopo deste trabalho, mas de

1 Endereço para correspondência: Avenida Itaú, $n^{0} 525$, Bairro Dom Cabral, Belo Horizonte, MG, Brasil. CEP: 30.535-012. E-mail: jleite. bhe@terra.com.br qualquer modo impressiona a força da obra foucaultiana na produção bibliográfica em psicologia no Brasil.

Essa penetração em domínios diversos é consoante com a diversidade temática de suas pesquisas, de matriz filosófica, abarcando domínios distantes do mainstream da área,ou seja, os estudos da própria história da filosofia. Reportando-se à sua trajetória Foucault (1980/2010a) rememora: "Fazer filosofia, então, e como hoje, significava, principalmente, fazer a história da filosofia" (p. 296). Ao invés de debater com os autores clássicos da área Foucault se debruçou, por um lado, sobre a psiquiatria, a medicina, as ciências humanas, as prisões, a sexualidade, as artes da existência grecoromanas (em seus livros), e por outro, sobre o inquérito, a anormalidade, a soberania, o Estado, o neoliberalismo, as práticas de governo de si e dos outros (em seus Cursos no Collège de France), para apontar alguns dos temas que não foram diretamente transpostos para livros. Seus estudos trabalhavam com séries históricas bem circunscritas, na Europa, entre os séculos XVII e XIX, e em seus trabalhos finais, na antiguidade greco-romana, com a exceção de seu estudo sobre o neoliberalismo contemporâneo (Foucault, 2004/2008b). Entretanto, seu objetivo não era uma análise histórica stricto sensu, mas abordar o que ele considerava o mais importante problema filosófico: a questão do tempo presente e o que "somos nós neste exato momento" (Foucault, 1982/1995, p. 239). Em outra ocasião ele formulou seu foco da seguinte maneira: 
Meu problema era fazer eu mesmo, e de convidar os outros a fazerem comigo, através de um conteúdo histórico determinado, uma experiência do que somos, do que não é apenas nosso passado, mas também nosso presente, uma experiência de nossa modernidade de tal forma que saíssemos transformados (Foucault, 1980/2010a, p. 292).

Temos aqui dois aspectos inovadores da obra foucaultiana. O primeiro é o exercício filosófico de modo pouco convencional em um campo "estrangeiro" de estudos históricos. O segundo, na comunicação de seus resultados mediante a formulação de um texto-experiência, que para além do conteúdo trouxesse ao leitor um tipo de experiência transformadora, não somente do que se pensa, mas também do que se é: "Sou um experimentador no sentido em que escrevo para mudar a mim mesmo e não mais pensar na mesma coisa de antes" (Foucault, 1980/2010a, p. 290), o que também se aplicava a seus leitores. Ainda nessa mesma entrevista de 1980, Foucault comenta como a pesquisa expressa em Vigiar e Punir, que alcançava até o período de 1830 , era percebida pelos leitores, favoráveis ou não às suas ideias, como uma descrição da sociedade disciplinar atual. Esse segundo aspecto inovador, no modo de redigir os resultados de suas pesquisas através de um texto-experiência, era compartilhada por pensadores franceses de sua geração, como Gilles Deleuze e Jacques Lacan. Para esses seus contemporâneos a escrita era inseparável da produção de uma experiência de transformação do que se pensa e do que se é, e não apenas uma suposta reprodução fidedigna da realidade estudada. Críticos da noção de representação, Foucault e alguns de seus contemporâneos buscaram outro formato e outra função para a escrita, em consonância com a expressão artística e literária. Talvez, por essa razão, a recepção do pensamento desses autores na França e em outros países, está marcada por um tipo de adesão eivada de encantamento, conduzindo a certa apropriação fetichista de seus textos, através do recurso à citação desses autores como argumento de autoridade e valor autoevidente, sem problematizá-los, cujas consequências não são as melhores.

Este tipo apropriação vai na contramão do uso feito por Foucault de seus autores de referência. Ele os utilizava, sem necessariamente ter que citá-los como uma "pequena peça autenticadora" do argumento desenvolvido. Mencionava como exemplo o fetichismo criado em torno de Marx cuja senha de ingresso era a citação do autor que afiançava sua adesão ao grupo. Por outro lado, numa menção à importância de Nietzsche em sua trajetória filosófica, Foucault (1975/2003a) diz: "[as] pessoas que eu gosto, eu as utilizo" (2003, p. 174), sendo esta a marca maior de reconhecimento, para além da citação. Esse uso do autor como instrumento de construção dos próprios argumentos, diverge do uso que muitos fazem de sua obra como peça autenticadora de valor vicário, onde a citação confere grau de qualidade ou de autoridade no debate das ideias. Enfim, um uso bastante distante do que Foucault valorizava como forma de expressão de um pensamento crítico. Por conseguinte, a ideia de inovação em Foucault, passa ao largo da citação a autores tidos como inovadores.

Há que se ressaltar que a inovação tem se tornado um forte valor contemporâneo, tanto no universo empresarial quanto no acadêmico. Basta ver como ela comparece como elemento de avaliação para o financiamento de projetos de pesquisa junto às agências de fomento no Brasil, reproduzindo uma tendência que também ocorre nos países desenvolvidos. Isso alcança também o campo dos métodos de pesquisa, produzindo uma vasta literatura que reivindica a utilização de métodos inovadores, como uma estratégia competitiva no mercado acadêmico, principalmente nas pesquisas de matriz qualitativas. Mesmo assim, existem estudos que advertem sobre os riscos do abuso presente nessa tendência, que pode gerar apreensões superficiais de questões complexas (Travers, 2009). Outros advertem que essa tendência pode "encorajar um foco no último modismo metodológico" em detrimento do aperfeiçoamento dos métodos mais estabelecidos, além tomá-los, rapidamente demais, como antiquados ou mesmo inapropriados (Wiles, Crow, \& Pain, 2013, p. 601). Assim, sem negligenciar o valor e a importância da inovação teóricometodológica, esses estudos buscam ponderar os riscos presentes nessa tendência bastante incentivada. Direção similar toma este trabalho.

Como um dos usos da ideia de inovação se ancora na referência a autores considerados inovadores, este estudo busca se contrapor a essa tendência presente na literatura.Seu objetivo é realçar outra faceta de Foucault: a utilização de elementos metodológicos clássicos em suas pesquisas. Defendo a perspectiva de que seu trabalho estava alicerçado em métodos rigorosamente construídos, explicitamente apresentados e compostos por muitos elementos clássicos. Assim, suas contribuições para os campos teóricos e metodológicos, não prescindiam de um diálogo produtivo com tradições consolidadas. Para isso trabalho a partir de três eixos analíticos. No primeiro, analiso a partir de fragmentos da obra desse autor com realce para seus Cursos, nos quais a exposição de método de seus estudos era frequente, delineando suas principais escolhas metodológicas; no segundo, estabeleço aproximações entre seu percurso e a literatura contemporânea sobre métodos de pesquisa em ciências humanas, principalmente as estratégias antropológicas; finalmente, exploro sua preocupação em oferecer uma exposição detalhada das razões de suas escolhas de método em suas pesquisas,o que é considerado um importante critério de qualidade de pesquisas em ciências humanas.

\section{Método em Foucault}

Uma definição preliminar e genérica de método poderia ser: "Caminho pelo qual se chegou a determinado resultado", mesmo quando ocorre de não ser previamente fixado (Lalande, 1926/1993, p. 678). Uma segunda acepção, retirada da mesma fonte, do método, define-o como "programa que regula antecipadamente uma sequência de operações a executar e que assinala certos erros a evitar" tendo em vista a obtenção de um resultado (p. 679). Em comum as definições entendem que o método implica um percurso com procedimentos ordenados que visam alcançar determinado resultado. A diferença entre ambas acepções está na necessidade de que esse processo seja previamente definido ou não. Sabemos que, se por um lado, nosso modelo hegemônico de produção científica preconiza a definição a 
priori desse percurso investigativo, por outro as pesquisas em ciências humanas consideram certo "artesanato" progressivo na organização da pesquisa, no qual instrumentos e objetos são paulatinamente refinados (Becker, 1992/1999).

Vejamos como essas duas dimensões de método comparecem na obra de Foucault. Nela não encontramos um texto definitivo sobre seu método. Sua discussão metodológica é marcada pela variabilidade, ainda que, como veremos adiante, ele se mantenha ligado a certos princípios gerais.

Não tenho um método que se aplicaria, do mesmo modo, a domínios diferentes. Ao contrário, diria que é um mesmo campo de objetos que procuro isolar, utilizando instrumentos encontrados ou forjados por mim, no exato momento em que faço minha pesquisa, mas sem privilegiar de modo algum o problema do método [...] Eu tateio, fabrico como posso instrumentos que são destinados a fazer objetos. Os objetos são um pouquinho determinados pelos instrumentos, bons ou maus, fabricados por mim. [...] Procuro corrigir meus instrumentos através dos objetos que penso descobrir, e, neste momento, o instrumento corrigido faz aparecer que o objeto definido por mim não era exatamente aquele. É assim que eu hesito ou titubeio (Foucault, 1980/2003c, p. 229).

Dois aspectos dessa citação merecem ser salientados. Em primeiro lugar, se entendermos método como sendo um conjunto de instrumentos operados mediante uma sequência de procedimentos a serem executados numa pesquisa, podemos dizer afirmar que não existe um (único) método foucaultiano. Ele considera o método deve ser escolhido caso a caso, a partir da construção do problema ou objeto da pesquisa. Este deve conduzir o pesquisador na escolha das estratégias, instrumentos e arranjos. Em decorrência disso, o método entendido como caminho para se chegar a um resultado, não é um apriori da pesquisa. Pelo contrário é algo que pode ser revisto, retificado ou alterado durante o processo da pesquisa.

De certa perspectiva podemos afirmar que Foucault trabalhou majoritariamente com um método consagrado por outra área de conhecimento, a História: a pesquisa documental. Lemke (2013) considera que os estudos de Foucault obedeciam aos "critérios tradicionais do trabalho historiográfico", podendo por isso serem criticados na argumentação e escolha do material (p. 31). Entretanto, não se trata de situar Foucault como um historiador, mas de reconhecer que seu trabalho filosófico era ancorado em pesquisas históricas, ou como ele mesmo define: "Meus livros não são tratados filosóficos nem estudos históricos; no máximo fragmentos filosóficos em canteiros históricos" (Foucault, 1980/2003d, p. 336). A formulação de "fragmentos" ao invés de "tratados" indica seu desinteresse em construir uma filosofia sistemática, mesmo que retrospectivamente em várias ocasiões buscasse realizar um alinhamento coerente entre diferentes momentos de sua investigação. Por certo não era um trabalho de historiador, mas o trabalho de um filósofo que buscava colocar problemas a partir de "suas formas mais singulares e concretas", e por isso tratava sempre de "questões localizadas e particulares" (Foucault, 1980/2010a, p. 335). Essa busca por uma problematização ancorada em elementos palpáveiso afastou das pesquisas em história da filosofia, em direção de uma pesquisa filosófica em canteiros históricos específicos, como a loucura, a prisão, a sexualidade, o sujeito moderno. Entretanto, essa ancoragem no estudo de problemas localizados, não o impedia, por outras vias, de abordar problemas gerais, afinal, ele afirmava, "o domínio da razão [investigado na História da Loucura] não é tão geral quanto o domínio da burguesia?" (Foucault, 1980/2010a, p. 336).

Para Foucault, tratava-se de pesquisar a partir de um campo empírico localizado e nesse nível colocar as questões cruciais, para num segundo momento elaborar generalizações e conceitos mais amplos. Sua formulação prescrevia que "as articulações teóricas são elaboradas a partir de um certo campo empírico", o que chamava de problematização (Foucault, 1984/2004e, p. 242). Rastreando algumas de suas principais formulações metodológicas presentes em seus Cursos e livros, torna-se evidente que esses eixos de trabalho são centrais em sua obra. Trabalharei aqui com na exposição de cinco dessas referências para na sequência aprofundar as marcas das escolhas metodológicas foucaultianas.

No curso Em defesa da sociedade (1999), proferido em 1976, Foucault discorre sobre quatro"precauções de método": apreender o poder "nas suas formas e instituições mais regionais e locais"; analisá-lo em "suas práticas efetivas e reais"; observar seu funcionamento reticular e não homogêneo; e realizar uma análise ascendente e indutiva, não dedutiva do poder (p. 32-36). Estas precauções, qualificadas como sendo de prudência, são retomadas no primeiro volume da História da Sexualidade (1988), com algumas modificações, sendo a principal a ênfase sobre a primazia das resistências como o "interlocutor irredutível" das relações de poder (p. 92).

Em Segurança, território e população (2008a), proferido em 1977, discorre sobre cinco proposições, não princípios ou regras, sobre a análise sobre a análise dos mecanismos de biopoder: 1) não se busca uma teoria geral, mas simplesmente saber por onde, como, por quem, quais procedimentos e com que efeitos; 2) as relações de poder não são fundadas em si mesmas, mas imanentes ao conjunto das relações sociais; 3 ) sua análise pode se abrir para uma análise global da sociedade; 4) não há discurso teórico ou imperativo, mas indicadores táticos; e, 5) finalmente, se há uma relação desgastada entre luta e verdade, resta um imperativo: nunca fazer política (p. 3-5).

O Nascimento da biopolítica (2008b), proferido em 1979, apresenta a "opção de método" de sua pesquisa naquele momento: em vez de partir dos universais (soberanos, Estado, sociedade civil) para deles deduzir fenômenos concretos, partir das práticas concretas e, num segundo momento, "passar os universais pela grade dessas práticas". Por conseguinte, sua principal decisão teórica e metodológica era: "suponhamos que os universais não existem" (p. 5).

Em O governo de si e dos outros (2010b), proferido em 1982 , retoma o projeto geral de sua pesquisa em torno de "matrizes de experiências", tendo como direção de trabalho os três eixos que as compõem: formação dos saberes; matrizes normativas de comportamento; constituição do modo de ser do sujeito (p. 41). Esses eixos são retomados no segundo volume da História da Sexualidade (1984) na discussão voltada para a problematização do "sujeito de desejo" (p. 10). Nessa formulação feita no final de sua obra, 
há um movimento explícito de reordenar a trajetória de suas pesquisas em uma dimensão tripartite, nos eixos de saber, poder e subjetivação.

Finalmente, fora dessa série dos Cursos, há um verbete de enciclopédia, Foucault, redigido por ele próprio, sob o pseudônimo de Maurice Florence, no qual reafirma seu campo de pesquisa fundado na "história da emergência dos jogos de verdade" e apresenta seu derradeiro estudo sobre o sujeito, ou seja, as condições pelas quais "o sujeito faz a experiência de si mesmo em um jogo de verdade", apresentando suas três "escolhas de método" (Foucault, 1984/2004d, p. 235-237). A primeira delas é contornar os universais antropológicos para interrogá-los em sua constituição histórica; a segunda, inverter o procedimento de remontar ao sujeito constituinte realizando estudo das práticas concretas pelas quais um sujeito é constituído na imanência de um campo de conhecimento, o que permitiria dar visibilidade aos processos de uma experiência em que o sujeito e o objeto se constituem conjuntamente um em relação ao outro; enfim, dirigir-se à análise das práticas, abordando o campo pelo viés do que "se fazia" (p. 238). São as práticas, conjunto de maneiras de fazer mais ou menos regradas, pensadas e acabadas, concebidas ao mesmo tempo como modo de agir e de pensar, que permitem entender a constituição do sujeito e do objeto.

Podemos explorar quatro aspectos colocados por essas cinco discussões metodológicas aqui destacadas. $\mathrm{O}$ primeiro deles é a resistência do autor em oferecer princípios metodológicos fixos. Ele prefere falar em precauções, proposições, e quando fala em "escolhas de método" o acento está sobre a escolha, que não se arvora a propor diretrizes. Por isso o uso cuidadoso das palavras. Tal cuidado é consoante com sua convicção de que a pesquisa é uma experiência que acontece na conjuntura singular de um projeto, e nesse percurso decisões são tomadas. Mesmo havendo escolhas de método similares na trajetória de um pesquisador ou de um grupo de pesquisadores, essas escolhas devem ser submetidas à pertinência da construção de seu objeto dentro do processo da pesquisa.

O segundo aspecto seria entender,em sua obra, qual é a relação entre teoria e método.Uma boa síntese de resposta foi feita pelo próprio Foucault ao afirmar que seu trabalho tem como ponto de partida certo campo de práticas, local e historicamente delimitado, a partir do qual suas grandes articulações teóricas são elaboradas. Portanto os grandes conceitos foucaultianos tais como sociedade disciplinar, biopolítica não são pontos de partida para suas análises, mas pontos de chegada que emergem de detalhados estudos de práticas locais. Como observou Nealon (2008),

[...] não há mais do que uma dúzia de páginas nos livros de Foucault (D\&P 23-31; HS1 92-98) em que ele manifesta e esquematicamente discute o status teórico do poder. [...] Quase todo o levantamento importante (teórico e prático) nos livros de Foucault é produzido na efetivação (enactment) de suas análises, em vez da argumentação indutiva ou dedutiva de principios (p. 97).

Assim, partindo de meticulosas análises de práticas concretas de espectro local, de modo predominantemente indutivo $^{1}$, Foucault vai construindo certo arcabouço teóricoconceitual amplo, mantendo a advertência que o mesmo não deveria ser entendido como sistema circunscrito, mas antes como caixa de ferramentas a serem utilizadas em outros estudos e pesquisas. Por isso dizia não se apoiar em "um background teórico contínuo e sistemático" (Foucault,1980/2010a, p. 294). Tratava-se de experimentar as ideias para modificá-las e a partir das questões trazidas do estudo de certa realidade local. E a relação entre as ideias já formuladas e as práticas não era de aplicação, mas de experimentação em outros campos, afinal, "é preciso a cada passo confrontar o que se pensa" (Foucault, 1983/2004b, p. 219). Como sugere Lemke (2012), "Foucault sempre construía seus instrumentos analíticos na relação com o objeto histórico que ele concretamente estudava, sem fornecer uma 'teoria geral'”' (p. 99). Por essa razão, continua o autor, é estranho que seus conceitos tenham se tornado uma espécie de meta narrativa a ser utilizada para qualquer objeto de investigação. Daí, podemos deduzir que o uso atualmente tão disseminado dos conceitos foucaultianos, não percorra necessariamente o mesmo caminho investigativo utilizado por Foucault, o que vem sendo denunciado por diversos autores (Lemke, 2012; Koopman, 2013). Dito de outro modo, reproduzir os conceitos aos quais Foucault chegou não equivale a acompanhá-lo em seu percurso investigativo.

O terceiro aspecto central na trajetória foucaultiana é sua postura incisivamente nominalista, corporificada em sua permanente crítica aos universais. Foucault, em seu fazer como pesquisador, busca fazer surgir no que é considerado universal, uma singularidade contingencialmente produzida. Rompe-se assim com o estabelecimento da evidência cartesiana como critério de verdade, para, mediante problematização, realçar uma contingência não necessária e, portanto, passível de ser modificada, no curso do movimento analítico. Contingências e singularidades tomam o lugar do que vinha sendo considerado como "natural" e universal, no caminho de pensamento por ele percorrido. Ressalto aqui que sua posição nesse quesito é essencialmente metodológica e não epistemológica, pois não postula a inexistência dos universais, apenas propõe uma estratégia para abordá-los: "suponhamos que os universais não existem", visando submeter sua análise ao crivo das práticas concretas localizadas.

Por último, merece destaque um conceito que ganha forte inflexão em seus trabalhos finais, o de "experiência". O uso dessa noção sofreu variações na obra de Foucault. $\mathrm{Na}$ década de 1960 ele buscava delimitar as condições e os limites de experiências históricas, ainda com uma conotação voltada para seu significado cotidiano (Lemke, 2013). Na década seguinte o tema quase desaparece de sua pauta retornando nos anos 1980. Existe assumida influência de Blanchot e Bataille com suas respectivas acepções de "experiência do fora" e de "experiência limite", como sendo o que arranca do sujeito de si e acarretando sua fragmentação ou dissolução. Daí decorre o comentário de Foucault

1 Digo "predominantemente" por entender que as "escolhas metodológicas" foucaultianas de cunho inclusive teórico antecipam as condições da análise, concordando com a sugestão de Bernard e Ryan (2010) de que as pesquisas reais nunca são exclusivamente indutivas ou dedutivas. 
associando experiência e transformação, que a pesquisa deve transformar o pesquisador levando-o a tornar-se outro e "não mais pensar na mesma coisa de antes" (Foucault, 1980/2010a, p. 290). Colocada ao lado de sua exposição, já citada, no Curso O governo de si e dos outros (2010b) reafirma-se que a experiência, no contexto da pesquisa, é um processo que atravessa e transforma, conjuntamente, sujeito (pesquisador) e objeto (problema de pesquisa), "um campo de experiências em que sujeito e objeto são ambos constituídos apenas em certas condições simultâneas, mas que não param de se modificar" (Foucault, 1984/2004d, p. 238). Assim, o acontecer da pesquisa não somente modifica o que pensa o pesquisador, como também, ao analisar o caráter e as correlações de seu objeto, em seus eixos de saberes, poderes e subjetivações, configura-o como entidade contingencialmente produzida e passível de ser transformada. A pesquisa torna-se um potencial instrumento de mudança de certo estado de coisas e instaurador de novas realidades. Um dos melhores exemplos desse tipo de experiência encontra-se em seu livro primal História da Loucura, descrito em uma entrevista como ligado às portas e fechaduras dos asilos, e que ele desejava que suas palavras, ligadas a essa materialidade, "atravessassem muros, fizessem saltar fechaduras, abrissem janelas" (Foucault, 1975/2006, p. 76).

A ideia de que a função primordial da pesquisa é transformar o mundo e não somente interpretá-lo, tem origem no século XIX (Marx, 1845/1974), mas ela ganha adesão ampla no último quartil do século XX (Geertz, 2001). Em Conferência Final do V Congresso Ibero-Americano de Pesquisa Qualitativa em Saúde em Lisboa a pesquisadora Madel Luz (2012) apresentou um panorama histórico e contemporâneo das tendências em pesquisa qualitativa. Segundo a pesquisadora, a força metodológica qualitativa atual residiria em sua capacidade de produzir resultados, de intervir no real, enfim, na capacidade de agir e não mais em compreender ou interpretar. Doravante, as ciências humanas e sociais também seriam regidas pela eficácia, por sua capacidade de produzir novas tecnologias e modos de intervenção. Esse diálogo entre o pensamento foucaultiano e a literatura sobre pesquisa qualitativa será aprofundado no segundo eixo, com foco na Antropologia.

\section{Foucault, pesquisas qualitativas e a antropologia}

Foucault não mantinha, em seus textos, uma preocupação exclusivista de diferenciar-se do trabalho de outros.Pelo contrário, fazia referências a trabalhos alheios similares aos seus, naquilo que considerou, em certo momento,como uma nova tendência em pesquisa, caracterizada pela "eficácia das ofensivas dispersas e descontínuas" (Foucault, 1999, p. 8).Assim, situava sua estratégia genealógica dentro de um conjunto de"pesquisas genealógicas múltiplas" (p. 13). No âmbito metodológico, também reconhecia utilizar-se de "métodos mais clássicos" (grifo meu), sem preocupação de, neste aspecto, ser original (Foucault, 1980/2010a, p. 292). O que mais o incomodava era a utilização de ideias gerais, como no caso da propalada frase de Reich "as massas desejavam o fascismo",como the foi perguntado em uma entrevista, desvinculadas de uma "análise histórica precisa"
(Foucault, 1977/2003b, p. 245).Por utilizar procedimentos clássicos de pesquisa histórica, considerava que seu trabalho poderia ser "verificado ou invalidado", numa possível alusão à discussão popperiana fortemente presente nos anos 1970, na qual a condição de um postulado científico se afirmar é decorrente de sua capacidade de passar por outros testes ao longo do tempo. Contudo, contemporaneamente, a discussão sobre cientificidade avançou por outros caminhos, nos quais boa parte das ciências humanas e sociais têm se mostrado menos dependentes do modelo das ciências naturais para afirmarem seu valor a partir de suas características peculiares. A matematização do mundo, inaugurada pela revolução científica do século XVII e formalizada por Descartes, marca da confiabilidade do pensamento científico-natural quantitativo, tem tido que compartilhar espaço junto a outros critérios de validade, distintos dos critérios das ciências naturais. Nesses estudos, elementos quantitativos essenciais como o tamanho da amostra, cedem lugar ao necessário aprofundamento da análise, mesmo em situações singulares onde o $\mathrm{n}$ equivale a um, como nos estudos de casos e nas etnografias.

Nessa direção, Becker (1999) denuncia o padrão comum das pesquisas quantitativas: "preocupação com métodos quantitativos, com a concepção a priori da pesquisa, com técnicas que minimizem a chance de obter conclusões não confiáveis devido à variabilidade incontrolada de nossos procedimentos" (p. 19). Nesse caso, os procedimentos recomendados têm em comum a diminuição da área onde o julgamento humano pode operar, substituindo-o pela aplicação de uma regra de procedimento. Curiosamente, segundo Becker, na sociologia americana, os trabalhos mais premiados lançaram mão de outros recursos metodológicos (observação participante, pesquisa histórica e estratégias de triangulação de procedimentos) diferentes dos recomendados, trabalhando com o que considera um modelo artesanal de ciência, "no qual cada trabalhador produz as teorias e métodos necessários para o trabalho que está sendo feito [...] os sociólogos deveriam se sentir livres para inventar os métodos capazes de resolver os problemas das pesquisas que estão fazendo" (Becker, 1999, p. 12).

Atualmente, a posição de Becker, de valorizar a relevância da construção de estratégias metodológicas capazes de lidar com problemas de pesquisa complexos, tem se tornado cada vez mais comum no campo das metodologias qualitativas (Brikmann, 2012). Desde os anos 1950 iniciou-se uma renovação dos métodos qualitativos que se intensificaria nas décadas seguintes, principalmente nos anos 1970, reagindo de um lado à falta de relevância de estudos empíricos padronizados, e de outro, aos excessos especulativos das grandes teorias sem fundamento na experiência. Um dos elementos fortes dessa tendência, que em absoluto não suplantou a anterior, se deu na consideração da subjetividade na experiência de pesquisa. Se inicialmente a preocupação maior era com a disciplinarização do viés subjetivo (bias) do pesquisador incidir sobre a pesquisa, parte-se atualmente do reconhecimento de que a pesquisa está ancorada "na experiência integral" do pesquisador, "sua apreensão pessoal do mundo, sua do mundo, seus sentimentos, suas intuições, seus valores" (Laperrière, 2010, p. 414). Em função disso esse a subjetividade torna-se um fator que deve ser evidenciado 
no curso da pesquisa, recebendo inclusive tratamento analítico, de modo a evitar subjetivismos idiossincráticos, e não deixada de lado, permitindo seu retorno insidioso e inconsciente. Desde então, temas como reflexividade, análise da implicação, entre outros, passaram a compor a discussão metodológica das pesquisas qualitativas (Silva, 2007).

$\mathrm{O}$ que encontramos hoje em relação às metodologias qualitativas é um campo multifacetado, contendo diferentes matizes epistemológicos, que vão desde enfoques mais realistas a outros mais construtivistas, com uma crescente convicção de que a qualidade científica de uma pesquisa não decorre do tamanho da amostra, nem da natureza qualitativa ou quantitativa, mas de seu desenho ao mesmo tempo rigoroso e pertinente (Flick, 2009, Laperrière, 2010). Isso não que dizer que esse pluralismo não comporte prevalências. Na verdade as abordagens metodológicas de matriz científico-natural prevalecem sobre as mais artesanais quando se trata de busca de fomento, ou mesmo avaliação pelas agências governamentais. $\mathrm{O}$ caso da Psicologia no Brasil é ilustrativo disso. Apesar da intensa presença de estratégias qualitativas no campo, os quatro Programas de Pós-Graduação classificados, em 2010 pela CAPES, com conceitos acima de 5 , trabalham preferencialmente com estratégias metodológicas quantitativas e experimentais.

Brinkmann (2012) qualifica a influência dessa condição no campo qualitativo como a Mcdonaldização dos métodos, demarcados pelos parâmetros da eficiência, da possibilidade de cálculo, da previsibilidade e do controle, elementos mais compatíveis com o financiamento das pesquisas e de origem no campo dos métodos quantitativos. Em resumo, apesar de contarmos hoje com uma pluralidade de métodos, os parâmetros de avaliação não sofreram alterações na mesma medida.

Mesmo assim, boa parte da literatura contemporânea sobre métodos qualitativos está bem mais afinada com as discussões promovidas por Foucault, do que tínhamos anteriormente, e não é debalde que ele seja citado como referência em tantos trabalhos. O que viso salientar aqui é que o diálogo com as tradições metodológicas longe de representar uma posição conservadora, podem possibilitar a construção de aportes inovadores com ancoragens mais consistentes.

Um forte elemento de conexão entre o trabalho de Foucault e estratégias convencionais de pesquisa se deu exatamente em relação àmais antiga delas nas ciências sociais, criadora dos primeiros procedimentos metodológicos qualitativos no início do século XX: a antropologia. Desde seu livro As palavras e as coisas, publicado em 1966, Foucault faz repetidas menções à etnologia considerando-a como sendo um dos saberes privilegiados da modernidade, por desenvolver um perpétuo princípio de crítica e inquietude face ao conhecimento estabelecido (Foucault, 1987a). Dentre várias outras menções principalmente feitas em entrevistas, destaco uma: "Eu poderia defini-la [minha pesquisa] como uma análise de fatos culturais que caracterizam nossa cultura. Nesse sentido, tratar-se-ia de algo como uma etnologia da cultura a que pertencemos" (1967/1994, p. 605).

Essa identificação com a pesquisa etnográfica não possui apenas um sentido figurado, mas também uma aproximação metodológica. Saliento aqui a desvalorização dos saberes chamados universais em função do que os antropólogos chamam de "saber local", fundamento das pesquisas etnográficas. Geertz (2001) considerava que os saberes universais sofriam dos males da banalidade e da irrelevância. Em contrapartida, no saber local "o reconhecimento direto e franco dos limites - um dado observador, num certo momento e num dado lugar - é uma das coisas que mais recomendam todo esse estilo de realizar pesquisas" (2001, p. 127). Tratase assim, de um observador situado, que desse lugar onde se coloca, desenvolve suas observações. Se isso parece ser limitador, em outra visada permite a produção de dados circunstanciados, sem apresentar uma visão que viesse de lugar nenhum. Podemos nos perguntar sobre qual a validade de um saber circunscrito. A resposta de Geertz tem uma tonalidade ética. Sugere que se buscamos o controle técnico da vida social (que seria, segundo ele, o sonho de Bentham e o pesadelo de Foucault) um conhecimento universal justificaria ser buscado, contudo, se procuramos construir uma vida que valha a pena, devemos ter um projeto científico menos ambicioso.

Em face desse desenho de uma pesquisa enraizada na singularidade composta por um pesquisador, que está em dado momento em dado lugar, qual o critério para aferição de legitimidade à empreitada? Várias respostas foram produzidas nessa direção, entre as quais destacarei uma oferecida pela própria antropologia. Para o dado qualitativo não se configurar como frouxo, aleatório ou irrelevante, seu tratamento deve tomá-lo em sua complexidade. Importa trabalhar com o que Geertz chamava de "descrição densa" (thick description), não superficial. O detalhamento de um conjunto ampliado dos "ingredientes da situação" (Geertz, 1989, p. 7), em sua multiplicidade e variação, é o que permite produzir a consistência do dado, o que acarreta um trabalho intenso no campo (seja ele empírico, ou documental) e na análise do corpus da pesquisa.

Essa singularidade bem circunstanciada constitui-se uma firme ancoragem para a pesquisa, que no caso de Foucault não se referia a um âmbito empírico geográfico, mas históricogeográfico, através de séries históricas específicas, localizadas geograficamente na Europa, acessadas mediante um conjunto variado de documentos dos mais diversos tipos, passando por escritos da época, obras de arte, textos filosóficas, regulamentos e legislação, documentos oficiais ou pessoais, entre outros. O que ele chamava "acontecimentalização" era exatamente essa recuperação e análise do objeto de pesquisa tomado não como um invariante, mas como "uma experiência histórica singular" (Foucault, 1984, p. 10).

Essa noção foi exposta em um debate, sobre seu livro Vigiar e punir, com um grupo de historiadores em 1978. Nessa ocasião Foucault apresentou uma de suas mais cristalinas discussões sobre método. O primeiro sentido de acontecimentalizar é fazer surgir uma singularidade onde se imaginava existir uma constância histórica. Para isso importa reencontrar as conexões, jogos de força, bloqueios, que num dado momento formaram o que se tornará uma universalidade, uma necessidade, construindo uma "multiplicação causal", que consiste numa análise do acontecimento "segundo os processos múltiplos que os constituem"(Foucault, 1980/2003c, p. 339). O segundo aspecto desse procedimento visa constituir um "poliedro 
de inteligibilidade cujo número de faces não é previamente definido e nunca se pode considerar como legitimamente concluído", procedendo analiticamente, como reflete Foucault "por saturação progressiva e forçosamente inacabada" (p. 340). Ao mesmo tempo Foucault adverte que na medida em que caminhamos na decomposição do processo no interior do objeto estudado, mais devemos avançar na "construção de relações de inteligibilidade externa". Para ele, a "decomposição interna de processos e multiplicação das 'sacadas' analíticas caminham juntas" (Foucault, 1980/2003c, p. 340). Finalmente, esse movimento promove um polimorfismo crescente dos elementos, das relações e dos domínios de referência de um objeto "aberto" de pesquisa processualmente construído.

Assim, sua pesquisa sobre o encarceramento penal como acontecimento envolveu a definição de múltiplos processos concorrentes, as práticas precedentes, a comparação com outras experiências históricas como o manejo da peste, a análise dos processos de encarceramento, o aparato material e institucional do cárcere, as instituições e legislações, entre outros, que careciam ser decompostos e analisados. Contudo, o mergulho aprofundado no detalhe exigia, concomitantemente, a encontrar conexões com aspectos de inteligibilidade externa, como as práticas de escolarização, disciplina militar, organização hospitalar, enfim com o que chamará de sociedade disciplinar ampliada. Era essencial que seu objeto de pesquisa fosse analisado em conexão com processos sociais mais amplos, garantindo uma perspectiva de inteligibilidade externa em seu estudo de um objeto ao mesmo tempo contingente e pluralizado em sua constituição (multiplicação de causas, analisadas em seu poliedro de inteligibilidade).

Deleuze capturou bem a direção desenhada por Foucault, ao lembrar que se por um lado, havia entre ambos, "uma grande diferença de método"(1992, p. 107), por outro ambos tinham uma concepção comum de filosofia, e principalmente uma causa comum: "[n]ossa tarefa era analisar estados mistos, agenciamentos, aquilo que Foucault chamava de dispositivos. [...] uma cartografia que implicava numa microanálise (o que Foucault chamava de microfísica do poder e Guattari, micropolítica de desejo)" (Deleuze, 1992, p. 109).

Essa citação oferece uma versão precisa sobre o approach metodológico foucaultiano, ao descrevê-lo como uma microanálise de estados mistos, polimórficos, heterogêneos, contingenciais, em sequências históricas regionalmente delimitadas, numa geografia analítica do "local". Para desenvolver essa microanálise de estados mistos, devese superar uma leitura dualistade cunho maniqueísta. A compreensão de que o real comporta estados híbridos cuja análise deve contemplar o escrutínio das tensões e tendências misturadas, de modo a permitir intervenções com alguma precisão. Afinal, a preocupação de ambos é menos circunscrever o atual estado de coisas, mas revelar as fissuras do real ou "aquilo em que estamos em via de diferir" (Deleuze, 1992, p. 119). Sua definição desses estados mistos, chamados por ele de dispositivos, era definido por três aspectos. Em primeiro lugar é um conjunto de elementos heterogêneos, tais como "discursos, instituições, organizações arquitetônicas, decisões regulamentares, leis, medidas administrativas [...]. o dito e o não dito" (Foucault,
1979, p. 244). Em segundo lugar, existe uma relação dinâmica entre esses elementos, um jogo estratégico envolvendo mudança de posições e funções.Finalmente, um dispositivo é uma formação constituída num momento histórico preciso, visando responder a uma urgência. Dentro dessa arquitetura complexa, a análise de um dispositivo envolve a construção do "poliedro de inteligibilidade", composto por elementos internos e externos (no efeito explicativo em que essa distinção ainda se justifica), cuja saturação analítica tende ao inacabamento.

Lévi-Strauss (2012) caracterizava o projeto antropológico como marcado por uma ambição de construir uma totalidade sistemática mediante conexões de sentido entre conjunto de fatores. Assim, os pormenores jamais são tomados como variáveis independentes. O objeto antropológico se configura como composto por múltiplas variáveis interdependentes que devem ser analisadas em conjunto, especialmente no que têm em comum. Com estratégia similar Foucault propõe seu poliedro de inteligibilidade, sua microanálise de estados mistos, enfim sua análise de dispositivos concretos como estratégia investigativa face ao acontecimento estudado. Porém, não se trata de construir uma totalidade sistemática. Foucault buscava de um lado sustentar certo inacabamento do processo investigativo valorizando as diferenças em detrimento das semelhanças, e de outro assumir a dimensão política de intervenção associada a esse tipo de pesquisa.

Ao desenvolver o trabalho de um "intelectual específico", que se autoriza a fazer afirmativas apenas sobre o que pesquisou, Foucault não manifestava adesão a questões "de princípio". Tendo a concordar com a avaliação de seu amigo e colaborador Paul Veyne (2008) em seu livro sobre o pensamento e a obra de Foucault, que considera apesar de ser tido com "esquerdista", ele nunca foi um homem de esquerda ou de direita, mesmo que estrategicamente buscasse os "esquerdistas" como parceiros em suas lutas pontuais (p. 201). Indo além, Veyne recusa sua suposta pecha de revolucionário, sugerindo que, em política, Foucault era um "reformista" (p. 9). Ainda que esse desenho contraste com o imaginário mais popularizado de Foucault, tido como o arauto contra as disciplinas e o poder, temos fortes indícios de ser uma boa interpretação (Foucault, 1984/2003d). $\mathrm{Na}$ verdade Foucault "nunca denunciou as disciplinas" (Koopman, 2013, p. 96), pois não era esse o seu problema de princípio. Além disso, insistia, contra a interpretação em sua época, que "O poder não é o mal". Considerava que "O poder são jogos estratégicos" e não existem sociedades sem relações de poder (Foucault 1984/2003c, p. 284). O que ele investiga são "estados mistos", híbridos compostos por elementos heterogêneos, nos quais a avaliação do que é bom e do que é ruim é sempre perigosa e nunca definitiva. Talvez o texto que de modo mais contundente desfaz essa ideia de que fosse um homem de esquerda, ao menos no sentido mais convencional, é sua entrevista sobre a crise do WelfareState europeu, na qual evidencia o problema da relação entre "uma demanda infinita com um sistema finito" e reconhece a necessidade de reformas, mesmo sem detalhar qual sua direção (Foucault, 1983/2004a, p. 140). Para o bem ou para o mal, menos que um revolucionário, Foucault não passava de um "intelectual específico", que afirmava os resultados de pesquisas específicas, histórica e regionalmente localizadas, 
sem propor um plano generalizado para outras realidades. Sua politização não passava pela adesão fixa a programas ou ideias, mas por certo modo de fazer pesquisas visando produzir efeitos de transformação na realidade social e na do próprio pesquisador.

\section{Um pesquisador em seu passo-a-passo}

Um dos momentos nos quais Foucault expõe com maior detalhamento as razões de suas escolhas metodológicas encontra-se em sua última pesquisa sobre o sujeito de desejo (Foucault, 1984). Nela, encontramos a exposição de sua perspectiva teórico-metodológica assentada na noção de experiência, composta pelos eixos de saber, poder e subjetivação e construída a partir de sua trajetória de pesquisas anteriores. Em sua "construção do objeto", indica a utilização de aportes de dois estudiosos contemporâneos da antiguidade greco-romana, Peter Brown e Pierre Hadot, a colaboração direta do historiador Paul Veyne, além de seus próprios estudos anteriores, ou seja, possuía um marco teórico plural, consoante às necessidades da pesquisa em curso, e não exclusivamente nietzschiano como alguns imaginam. Esta tendência de pluralidade teórica tem sido cada vez mais constante nas pesquisas em ciências humanas e sociais (Luz, 2012).

Foucault reconhece que seus estudos são históricos, mas não o trabalho de um historiador, e sim "um exercício filosófico" (1984, p. 14). Esse é um dos poucos momentos onde se mostra reconciliado com sua condição de filósofo. Seus instrumentos de análise consistiam na distinção entre os elementos de código moral e os elementos de ascese, de práticas de si, privilegiando diferencialmente a abordagem dessas últimas. Seu corpus era composto pelos textos antigos de caráter prescritivo que tinham por alvo "propor regras de conduta", portanto, textos práticos e "operadores que permitiam aos indivíduos interrogar-se sobre sua própria conduta [...] conformar-se eles próprios como sujeito ético" (p. 16).

Vale salientar que o desenho metodológico dessa pesquisa não foi feito por antecipação. No momento em que esse projeto, iniciado em 1975 a partir do eixo das relações entre saber e poder, foi recolhendo elementos que davam realce ao tema da subjetividade. Isso o obrigou a realizar um deslocamento teórico-metodológico mais amplo. Portanto, suas escolhas teórico-metodológicas, que fazem parte da Introdução de seu livro (1984), são produzidas e justificadas posteriormente ao início da pesquisa, dentro da diretriz de trabalho que sempre acompanhou Foucault (1984) de "saber de que maneira e até onde seria possível pensar diferentemente em vez de legitimar o que já se sabe” (p. 13), marca de sua trajetória filosófica.

O objetivo dessa investigação era "estudar os jogos de verdade na relação de si para si e a constituição de si mesmo como sujeito" afinado com um projeto maior de realizar uma genealogia do sujeito moderno (1984, p. 11).A meta almejada era desfazer certo consenso à época de instituir a sexualidade no núcleo da subjetividade e promover alternativas a essa possibilidade. Em sua visão, o maior problema de seu tempo, e ainda talvez do nosso, seria liberar o sujeito do tipo de subjetivação hegemônica, ou seja, "promover novas formas de subjetividade através da recusa deste tipo de subjetividade que nos foi imposto há séculos" (Foucault, 1982/1995, p. 239).

Vemos que o trabalho de Foucault tem ressonâncias com as perspectivas quanto ao que se define como qualidade em pesquisa qualitativa. Essa é medida, entre outros critérios, pela explicitação de como a pesquisa é definida, administrada nas etapas desse processo de decisão e "produzida passo a passo" (Flick, 2009, p. 173). Foucault, no decorrer de sua obra teve o cuidado de expor para seus leitores e alunos qual foi seu caminho de investigação, quais foram suas escolhas metodológicas, justificando quando necessário suas mudanças de rota. Mantinha dessa maneira a virtude de um pesquisador clássico de ser explícito na exposição de como conduziu seu processo de investigação.

\section{Considerações Finais}

Este texto teve por meta complementar promover uma defesa do diálogo acadêmico universitário em detrimento do encastelamento segmentado de crenças e modos de fazer teórico-metodológicos, que se restringem a uma conversa entre semelhantes, cuja direção é, muitas vezes, reafirmar o que já se pensava antes. Tomou como parâmetro a trajetória de Foucault, que mesmo tendo suas preferências e rejeições, manteve, em diversos momentos, aberturas de conversações e leituras diversificadas, para além de seus autores de afinidade.

Fica ainda para ser realizado um estudo sobre a recepção e as modalidades do uso das contribuições foucaultianas nas pesquisas em psicologia no Brasil, o que demanda um desenho de investigação específico, que ultrapassa os objetivos desse artigo.

Diferentemente dos etnógrafos, Foucault tinha como corpus preferencial documentos e textos. Contudo mantinha existencialmente uma postura de etnógrafo de seu tempo, observando o que se passava, perscrutando permanentemente quem somos nós em um dado momento, onde está nosso intolerável. Isso tinha numa relação direta com suas pesquisas, consideradas "fragmentos de autobiografia", não apenas no sentido pessoal, mas também sócio-político. Suas pesquisas, de matiz histórico-documental, tinham por alvo final o presente por ele observado, como reconhece em Vigiar e punir, ao afirmar que aprendeu sobre a tecnologia política do corpo "mais pelo presente do que pela história Nos últimos anos houve revoltas em prisões em muitos lugares do mundo" (Foucault, 1975/1987b, p. 32). O mesmo ocorreu em relação à sua análise das relações entre poder psiquiátrico e loucura, intuídas no estágio de dois anos em Saint-Anne, como psicólogo, através conversas com os pacientes: "sem jamais ter que exercer o poder ligado ao saber psiquiátrico, eu podia observá-lo a cada instante" (Foucault, 1975/2006, p. 70-71). Entendo ter sido essa construção de problemas de pesquisa relevantes, associada ao trabalho detalhado e preciso, que contribuiu para o impacto incisivo de sua obra em nossos dias. Ele sempre insistiu: "É preciso entrar nos detalhes" (Foucault, 1984/2004e, p. 245).

Concluindo, seguir seu caminho não se faz pela trilha preguiçosa da citação ou pela reprodução dos mesmos 
problemas enfrentados por Foucault, mas pela construção de nossos próprios problemas e instrumentos de pesquisa, sem abdicarmos do diálogo com métodos clássicos, na medida em que podem ser úteis à nossa pesquisa. Em suma, pelo trabalho diligente que se diferencia da colagem do autor e ao mesmo tempo nos modifica no processo da pesquisa.

\section{Referências}

Becker, H. (1999). Métodos de pesquisa em ciências sociais. (M. Aguiar, Trad., 4a ed.).S ão Paulo: Hucitec. (Trabalho original publicado em 1992)

Bernard, H.,\& Ryan, G. (2010). Analyzing qualitative data: systematic approaches. Los Angeles: SAGE.

Brinkmann, S. (2012). Qualitative research between craftsmanship and McDonaldization: A keynote address form the 17th Qualitative Health Research, Conference. Qualitative Studies, 3(1), 56-68.

Deleuze, G. (1992). Conversações. (P. Pelbart, Trad.). Rio de Janeiro: ed. 34. (Trabalho original publicado em 1990)

Flick, U. (2009). Qualidade na pesquisa qualitativa. (R. Costa, Trad.) Porto Alegre: Artmed. (Trabalho original publicado em 2008)

Foucault, M. (1979). Sobre a História da Sexualidade. Microfísica do poder. (R. Machado, Trad.). (pp. 243-276) Rio de Janeiro: Graal.

Foucault, M. (1987a). As palavras e as coisas (4ªed., S. Muchail, Trad.). São Paulo: Martins Fontes.

Foucault, (1984). M. História da Sexualidade 2: a vontade de saber . (J. Albuquerque, trad.) Rio de Janeiro: Graal

Foucault, M. (1988) História da Sexualidade 1: a vontade de saber. $7^{\text {a }}$ ed. (J. Albuquerque, trad.) Rio de Janeiro: Graal (Trabalho original publicado em 1976).

Foucault, M. (1987b). Vigiar e punir. (L. Vassallo, Trad.). Petrópolis: Vozes.

Foucault, M. (1994) Qui êtes-vous, professeur Foucault? Dits et Écrits 1 1954-1988. (pp. 601-620). Paris: Gallimard. (Trabalho original publicado em 1967)

Foucault, M. (1995). O sujeito e o poder. InH. L. Dreyfus \&P. R. Rabinow (Eds.), Michel Foucault, uma trajetória filosófica (V. Portocarrero, Trad.) (pp. 231-249). Rio de Janeiro: Forense Universitária. (Trabalho original publicado em 1982)

Foucault, M. (1999). Em defesa da sociedade. (M. Galvão, Trad.) São Paulo: Martins Fontes. (Trabalho original publicado em 1997)

Foucault, M. (2003a). Entrevista sobre a prisão: o livro e seu método. Estratégia, Poder-Saber (V. Ribeiro, Trad.) (pp. 159174) Rio de Janeiro: Forense Universitária. (Trabalho original publicado em 1975)

Foucault, M. (2003b). Poder e saber. Estratégia, Poder-Saber (V. Ribeiro, Trad.) (pp. 223-240) Rio de Janeiro: Forense Universitária. (Trabalho original publicado em 1977)

Foucault, M. (2003c). Poderes e estratégias. Estratégia, PoderSaber. (V. Ribeiro, Trad.) (pp. 241-252) Rio de Janeiro: Forense Universitária. (Trabalho original publicado em 1977)

Foucault, M. (2003d). Mesa redonda de 20 de maio de 1978. Estratégia, Poder-Saber. (V. Ribeiro, Trad.) (pp. 335-351) Rio de Janeiro: Forense Universitária. (Trabalho original publicado em 1980)
Foucault, M. (2004a). Um sistema finito diante de um questionamento infinito. Ética, sexualidade, politica. (E. Monteiro; I. Barbosa, Trad.) (pp. 126-143) Rio de Janeiro: Forense Universitária. (Trabalho original publicado em 1983)

Foucault, M. (2004b). Política, e ética: uma entrevista. Ética, sexualidade, política. (E. Monteiro; I. Barbosa, Trad.) (pp. 218-224) Rio de Janeiro: Forense Universitária. (Trabalho original publicado em 1983)

Foucault, M. (2004d). Foucault. Ética, sexualidade, politica. (E. Monteiro; I. Barbosa, Trad.) (pp. 234-239) Rio de Janeiro: Forense Universitária. (Trabalho original publicado em 1984)

Foucault, M. (2004e). O Cuidado com a verdade. Ética, sexualidade, política. (E. Monteiro; I. Barbosa, Trad.) (pp. 240-251) Rio de Janeiro: Forense Universitária. (Trabalho original publicado em 1984)

Foucault, M. (2006). Eu sou um pirotécnico. In: Pol-Droit (ed.) Michel Foucault: entrevistas. (V. Portocarrero, Trad.) (pp. 69-100) Rio de Janeiro: Graal. (Trabalho original publicado em 1975).

Foucault, M. (2008a). Segurança, território, população. (E. Brandão, Trad.) São Paulo: Martins Fontes. (Trabalho original publicado em 2004)

Foucault, M. (2008b). Nascimento da biopolítica. (E. Brandão, Trad.) São Paulo: Martins Fontes. (Trabalho original publicado em 2004)

Foucault, M. (2010a). Conversa com Michel Foucault. Repensar a política. (A. Pessoa, Trad.) (pp. 289-347) Rio de Janeiro: Forense Universitária. (Trabalho original publicado 1980)

Foucault, M. (2010b). O governo de si e dos outros. (E. Brandão, Trad.) São Paulo: Martins Fontes. (Trabalho original publicado em 2008)

Geertz, C. (1989). A interpretação das culturas. Rio de Janeiro: LTC. (Trabalho original publicado em 1973)

Geertz, C. (2001). Nova luz sobre a antropologia. (V. Ribeiro, Trad.) Rio de Janeiro: Jorge Zahar. (Trabalho original publicado em 2000)

Koopman, C. (2013). Genealogy as critique: Foucault and the problems of Modernity. Bloomington: Indiana University Press.

Lalande, A. (1993).Vocabulário técnico e crítico da Filosofia. (R. Ferreira, Trad.) São Paulo: Martins Fontes. (Trabalho original publicado em 1926)

Laperrière, A. (2010). Os critérios de cientificidade dos métodos qualitativos In J. Poupart et al.(Eds.), A pesquisa qualitativa: enfoques epistemológicos e metodológicos. $2^{\mathrm{a}}$ ed. (A. Nasser, Trad.)(pp. 410-435). Petrópolis: Vozes. (Trabalho original publicado em 1997)

Lemke, T. (2012). Foucault, governamentality and critique. Boulder: Paradigm Publishers.

Lemke, T. (2013). Critique and experience in Foucault. Theory, Culture and Society, 28(4), 26-48.

Lévi-Strauss, C. (2012). A antropologia diante dos problemas do mundo moderno. (R. d'Aguiar, Trad.). São Paulo: Companhia das Letras. (Trabalho original publicado em 2011).

Luz, M. (2012, outubro). Ações e saberes plurais em pesquisas qualitativas em saúde. Conferência Final do $V$ Congresso Ibero-Americano de Pesquisa Qualitativa em Saúde. Lisboa, Portugal.

Marx, K. (1974). Teses contra Feuerbach (1974) In Os pensadores: Karl Marx (J. Giannotti, Trad.). São Paulo: Abril Cultural. (Trabalho original publicado em 1845). 
Nealon, J. (2008). Foucault beyond Foucault: Power and its intensifications since 1984. Stanford: Stanford University Press.

Silva, M. (2007). Reflexividade e implicação de um "pesquisadornativo" no campo da saúde mental: sobre o dilema de pesquisar os próprios "colegas de trabalho". Campos, 8(2), 99-115.

Travers, M. (2009). New methods, old problems: a skeptical view of innovation in qualitative research. Qualitative Research, 9(2), 161-162.
Wiles, R., Crow, H.,\& Pain, G. (2013). Innovation in qualitative research methods: a narrative review. Qualitative Research, 11(5), 587-604.

Veyne, P. (2008). Foucault: as pensée, as personne. Paris: Albin Michel. 